
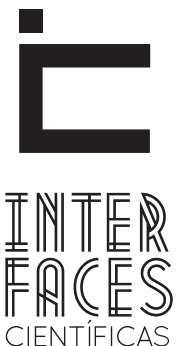

EDUCAÇÃO

\title{
A LUDICIDADE COMO PRINCÍPIO FORMATIVO
}

\section{RESUMO}

Muitos campos do conhecimento investigam as funções das atividades lúdicas no desenvolvimento humano. Orientar-nos-emos, neste artigo, a partir de pesquisa bibliográfica, por alguns recortes dos campos da filosofia, da antropologia, da sociologia e da psicologia. Aqui entendemos o conceito de lúdico sob duas perspectivas: a) o lúdico como uma dinâmica interna do sujeito que sente e vivencia uma experiência plena; e b) o lúdico como manifestação da realidade objetiva materializada em atividade ou ação cultural. Em grande medida, o conceito de ludicidade é confundido, ora com práticas recreativas, ora com atividades de lazer. Há uma polissemia em seu entorno, o que nos impele a uma investigação sobre o assunto. Temos por objetivo, pois, contribuir para com o deslindamento do conceito que desenvolvemos, acreditando que, como tal, ampliaremos a compreensão epistemológica referente aos processos de ensino e aprendizagem no âmbito de instituições educacionais, nos seus vários segmentos. Do quadro teórico que construímos, tomamos como principais referências: Gilles Brougere (1998), Donald Winnicott (1975) e Cipriano Luckesi (2004; 2006; 2007).

\section{PALAVRAS-CHAVE}

Ludicidade. Atividades lúdicas. Educação. Prática pedagógica 


\section{ABSTRACT}

Many fields of knowledge investigating the functions of recreational activities in human development. We will be guided through this article by bibliographic research, by some clippings from the fields of philosophy, anthropology, sociology and psychology. Here we understand the concept of ludic under two perspectives: a) The ludic as a subject of internal dynamic who feels and experience a full experiences; b) The ludic manifestation of objective reality as embodied in cultural activity or action. Largely, the concept of ludic is confused, sometimes with recreational practices, sometimes with leisure activities. There's a polysemy in its surroundings, what drives us to an investigation into the matter. Our goal is to contribute to the clarification of the concept that we developed, believing that, as such, we will extend the epistemological understanding regarding the processes of teaching and learning within educational institutions, in its various segments. The theoretical framework that we build, we take as main references: Brougère Gilles (1998), Donald Winnicott (1975) and Cipriano Luckesi $(2004,2006,2007)$.

\section{KEYWORDS}

Ludic. Ludic Activities. Education. Pedagogical Practice.

\section{RESUMEN}

Muchos campos de conocimiento investigan las funciones de las actividades lúdicas en el desarrollo humano. En este artículo nos orientaremos a partir de la literatura, por algunos recortes de los campos de la filosofía, de la antropología, de la sociología y de la psicología. Aquí entendemos el concepto lúdico desde dos perspectivas: a) la dinámica interna del sujeto que siente y prueba una experiencia plena, y b) como manifestación lúdica de la realidad objetiva que se concreta en actividad o acción cultural. En gran medida, el concepto de ludicidad se confunde a veces con las prácticas recreativas y as veces con actividades de ocio. Hay una polisemia en su entorno, lo que nos lleva a una investigación sobre el asunto. Nuestro objetivo, es contribuir para la clarificación del concepto que hemos desarrollado, en la creencia de que, como tal, vamos a ampliar la comprensión epistemológica respecto a los procesos de enseñanza y aprendizaje en las instituciones educativas, en sus diversos segmentos. Del cuadro teórico que hemos construido, tomamos como referencias principales: Brougère Gilles (1998), Donald Winnicott (1975) y Cipriano Luckesi $(2004,2006,2007)$.

\section{PALABRAS CLAVE}

Alegría. Actividades Lúdicas. Educación. Práctica Pedagógica.

\section{INTRODUÇ̄̃O}

O conceito de ludicidade é polissêmico. Em grande medida, ludicidade e atividades lúdicas são entendidas como expressões de um mesmo conceito, confundindo-se, respectivamente, o fenômeno - que pode ser observado subjetivamente, a partir da reali- dade interna do indivíduo - e o ato social (a ação como produto da cultura) realizado por um ou por muitos indivíduos.

Com este artigo, pretendemos contribuir para com 
a explicação do conceito que desenvolvemos, defendendo, ainda, o lúdico como princípio formativo nas práticas pedagógicas, acreditando que, como tal, ampliamos a compreensão epistemológica referente aos processos de ensino e aprendizagem no âmbito de instituições educacionais. Por acreditarmos que ensinar e aprender podem ser práticas extremamente prazerosas e criativas nesses contextos. E por não mais pretender ver esse princípio negado em espaços educacionais.

Lúdico vem do latim ludus que, de acordo com Huizinga: "abrange os jogos infantis, a recreação, as competições, as representações litúrgicas e teatrais, e os jogos de azar" (HUIZINGA, 2004, p. 41). Acrescenta que os jogos têm um profundo cunho estético, uma intensa e fascinante capacidade de excitar. Lúdico deriva também do radical latino In lusio que quer dizer ilusão, em jogo. Talvez essa característica explique a ideia de simulacro que reside por detrás do conceito.

Luckesi (2004) afirma que a atividade lúdica é aquela que propicia à pessoa que a vive, uma sensação de liberdade, um estado de plenitude e de entrega total para essa vivência. "O que a ludicidade traz de novo é o fato de que o ser humano, quando age ludicamente, vivencia uma experiência plena. [...] Não há divisão" (LUCKESI, 2006, p. 2).

Freud citado por Santos (2005) percebeu os significados psicológicos das brincadeiras e jogos para a elaboração interna do indivíduo. Após trabalhos iniciais com adultos, notou que na infância estava a origem dos transtornos mentais. Somente ao notar, com atenção, como uma criança de 18 meses brincava com um carretel, na casa de um amigo, ele desvelou a função psicológica do brincar. Freud compreendeu então que o jogo para a criança não é só prazer, é uma maneira de retornar as situações que the provocam angústia e, ao mesmo tempo, elaborar essas situações (SANTOS, 2005, p. 40).

À Melanie Klein, psicanalista alemã, coube a missão de mudar a abordagem da psicanálise e da educação infantil, a excessivamente corretiva. Discípula fiel de Freud, Melanie enfatizava as fantasias das crianças considerando-as como próprias e indispensáveis. Aprofundou o conceito de inconsciente, formulado por Freud, em razão, talvez, da observação de estágios mais primitivos da mente humana, ao lidar com crianças. Klein suavizou a maneira de encarar o sadismo, a crueldade, a sexualidade e a liberação das fantasias. Para conscientizar os conflitos internos, Klein cria a técnica lúdica: "Ao brincar, a criança está tão dominada pelo inconsciente que realmente é desnecessário recomendar-lhe que exclua deliberadamente as interferências conscientes. A técnica lúdica proporciona abundância de material e dá acesso aos estratos profundos da mente" (KLEIN apud SANTOS, 2005, p. 42).

Donald W. Winnicott (1975), psicanalista inglês, segue os princípios de Melanie Klein no tratamento terapêutico infantil via o brincar, mas vai além. Para ele, o brincar traz um sentido em si, está situado muito além de um instrumento, de um meio para compreender a criança e seus possíveis bloqueios. 0 interessante tema sobre as questões dos fenômenos e objetos transicionais é objeto de estudo de Winnicott. O fenômeno transicional trata, grosso modo, de uma área de experiência, na qual a criança inicia seu relacionamento com o mundo.

Para Bruno Bettelheim (1989), outro psicanalista dedicado ao universo infantil, a brincadeira é uma ponte para a realidade: propicia à criança a compreensão de como o mundo funciona. Por meio da brincadeira, as crianças aprendem o que podem o que não podem e como fazer com os objetos; aprendem as primeiras noções do "porque sim" e do "porque não”. Ao brincar com os outros, aprendem as regras da sorte, da probabilidade e as regras de conduta. Bettelheim (1989) afirma que a maior aprendizagem realizada pela criança ao brincar diz respeito à capacidade de saber perder. Com essa aquisição, ela compreende que os reveses da vida são temporários. 
Piaget, que tinha interesse mais epistemológico que pedagógico, descobriu que as pessoas aprendem por meio de suas atividades. 0 indivíduo age e compreende utilizando processos denominados de assimilação e acomodação. A pessoa procura semelhanças entre elementos que já sabe, em um novo conhecimento, "assemelhando-os". Depois, faz a apreensão dos elementos que ainda não sabe, "acomodando-os" num novo patamar para uma nova assimilação. 0 processo é dialético. As atividades humanas são consideradas jogos, de acordo com Piaget, e esses são classificados em três tipos: os jogos de exercício, os jogos simbólicos e os jogos de regras. Enquanto a psicanálise observa as brincadeiras como auxílio para a cura emocional do indivíduo, Piaget citado por Luckesi (2006) as concebe como recurso que o sujeito utiliza para o desenvolvimento da cognição e da afetividade.

Vygotsky vê a brincadeira de faz-de-conta, ou o jogo simbólico, ou ainda, o jogo de papéis como um lugar de desenvolvimento. Para ele, a aprendizagem permite que o sujeito se desenvolva, e não o contrário, ou seja, que a aprendizagem se realiza de acordo com o estágio de desenvolvimento do indivíduo. Naquela perspectiva, a criança, ao brincar de faz-de-conta, transita pelo mundo da imaginação, mas regido por regras. Por exemplo, a criança ao brincar de escola é limitada pelas regras de funcionamento de uma escola - mesmo em imaginação tem que ter regras. Portanto, essa brincadeira, que é uma atividade que se realiza fora da criança é aprendizagem e favorece o desenvolvimento "num caminho tipicamente humano, definido por um percurso que está atrelado à cultura" (KOHL, 2011) ${ }^{3}$.

Esses psicólogos e psicanalistas observaram os procedimentos emocionais e também cognitivos (como foi o caso de Jean Piaget) desencadeados pelas atividades lúdicas. Para os psicanalistas, a exemplo de Freud, Klein, Winnicott, Betelheim, as brincadeiras foram abordadas como possibilidade de reconstrução do passado traumático e construção de um cotidiano criativo e saudável.

Para fundamentar nossa concepção do que seja ludicidade e a ação de brincar, os estudos de Winnicott (1975), Luckesi (2006), assim como as contribuições de Brougère (1998), faz-se fundamental. Nesse sentido, dedicamos especial interesse a esses autores nos próximos tópicos.

3 Vídeo em que Marta Kohl de Oliveira, professora da Universidade de São Paulo, apresenta conceitos fundamentais de Lev Vygotsky, destacando sua importância para a educação. KOHL, Marta. In: http://www.youtube.com/ watch?v=mj2XBkwTVDw\&feature=related. Acessado em: 22 dez. 2011.

\section{LUGAR DA LUDICIDADE E DO BRINCAR NO NOSSO ESTUDO}

\subsection{AS CONTRIBUICÕ̃ES DE WINNICOTT}

Médico e psicanalista, o inglês Donald Winnicott encontrou um interessante campo de estudo ao perceber etapas fundamentais do desenvolvimento humano. Constatou, por exemplo, o quanto o brincar no início da vida concede um importante suporte à construção da identidade pessoal. E suas conclusões foram e continuam sendo preciosas para o trabalho dos educadores.

No seu livro, O Brincar e a Realidade, escrito nos anos 1960, Winnicott defende a sua tese central: a existência de um estádio que precede a objetividade ou a capacidade de percepção objetiva da realidade. Para o estudioso, o bebê vive num mundo subjetivo, e a mudança deste estado primário para um estádio em que a percepção se torna possível, não é tão natural quanto parece ser, consiste num processo que precisa 
ser compreendido e assistido a fim de que o sujeito se desenvolva de forma saudável.

0 autor se refere, no seu trabalho, aos objetos transicionais, não ao objeto em si, mas, sobretudo, ao paradoxo envolvido no uso que o bebê dá ao objeto transicional, solicitando aceitação, tolerância, respeito e que não seja resolvido tal paradoxo, porque a criança possui valor para todo o indivíduo humano que seja capaz de ser enriquecido pela exploração do vínculo cultural com o passado e com o futuro. Winnicott reluta em fornecer exemplos relacionados aos fenômenos transicionais por achar esse processo universal e de variedade infinita, como um rosto humano.

Em sua hipótese original, Winnicott destaca que pode ser lucrativo estudar o desenvolvimento entre dois conjuntos de fenômenos, ocorrentes com bebês, que são separados por um intervalo de tempo: o uso dos punhos, dos dedos e dos polegares em estimulação da zona erógena oral; e, após alguns meses, passam a gostar de brincar com bonecas e objetos especiais permitidos pela maioria das mães para se tornarem apegados a tais objetos.

Para Winnicott, a primeira ligação da criança com o mundo dá-se pela relação com a mãe. Não há bebê sem uma mãe - que pode não ser a biológica, mas aquela que assume o papel da mãe boa o bastante ou não boa o bastante - que responde, ou não, adequadamente aos diferentes estágios de desenvolvimento do bebê. 0 brincar é a base da vida cultural. Não está dentro, tampouco está fora, melhor dizendo, o brincar é um recurso externo intimamente ligado à subjetividade do sujeito (ao seu mundo interno). Para controlar o que está fora dele, o sujeito precisa se mobilizar e fazer coisas, não basta pensar ou desejar, ou seja, o brincar é fazer algo (WINNICOTT, 1975).

Na visão do autor, o brincar evolui, ou se desenvolve a partir da relação do bebê com os objetos transicionais. Este espaço/tempo em que aquele descobre uma sensação de onipotência estabelecida pela confiança na relação com a mãe. Essa sensação de onipotência provém do "controle" que o bebê passa a exercer sobre o real. A zona onde a ideia de magia se origina se estabelece por meio da confiança sentida pelo bebê, visto que até certo ponto experimenta onipotência. Magia, ilusão - in lusio - ludos - lúdico: experiência onipotente - o seio da mãe é uma criação do bebê. Os objetos - seio, mamadeira, fralda e outros - serão, posteriormente, o elo com a vida cultural; entre realidade objetiva e realidade subjetiva ; a possessão não-eu.

Os objetos transicionais prolongam o período em que o bebê se acredita onipotente, aos poucos, ele substitui essa crença e passa a aceitar uma realidade sobre a qual não tem controle. 0 bebê se vê com poderes mágicos e, com o tempo, percebe a ilusão. Mas, com as brincadeiras e o aprendizado do mundo, a criança, o adolescente e o adulto retêm o poder de criar e adaptam-se às possibilidades reais.

No que concerne à educação, interessante pensar que, nas palavras do autor, o professor visa ao enriquecimento, o terapeuta preocupa-se com os processos da criança e seus desbloqueios: "pessoas responsáveis devem estar disponíveis quando as crianças brincam, mas isso não significa que precisem ingressar no brincar" (WINNICOTT, 1975, p. 75). O brincar possui tudo em si - é autocurativo.

É no brincar que se pode ser criativo e utilizar sua personalidade integral - é somente sendo criativo que o indivíduo descobre o eu (self). No capítulo destinado ao estudo da criatividade e suas origens, Winnicott, apresenta um conceito de criatividade do ponto de vista da experiência humana, esclarecendo as origens do potencial criador e a influência dos relacionamentos afetivos na conquista da maturidade psicológica, que naturalmente pressupõe a posse e utilização da liberdade e criatividade pessoal, ao longo da vida. Refere-se à criatividade como um estado de prazer, contrário à atitude de submissão. Os indivíduos sentem que a vida merece ser vivida ou, então, que não podem viver criativamente e têm dúvidas so- 
bre o valor do viver. 0 autor afirma que a criatividade que lhes interessa é uma proposição universal, que se relaciona ao estar vivo.

Aqui particularmente a dimensão da criatividade se faz fundamental. A ideia de criatividade que Winnicott desenvolveu não está relacionada à ideia da criação das obras-de-arte; se refere ao modo do sujeito abordar o meio que o circunda. Em outras palavras, o impulso criativo pode ser considerado como algo em si, e que se faz presente na vida de qualquer indivíduo, ainda que necessário para o artista. Isso não significando que o artista que produz objetos artísticos, até de excelência na qualidade ou um compositor que produz peças maravilhosas, necessariamente, possui um viver criativo. Winnicott não teve interesse de explicar o impulso criativo, e até duvida dessa possibilidade, mas procurou estabelecer uma ligação entre viver criativo e o viver propriamente dito:

Supondo-se uma capacidade cerebral razoável, inteligência suficiente para capacitar o indivíduo a tornar-se uma pessoa ativa e a tomar parte na vida da comunidade, tudo o que acontece é criativo, exceto na medida em que o indivíduo é doente, ou foi prejudicado por fatores ambientais que sufocaram seus processos criativos (WINNICOTT, 1975, p. 98-99).

A criatividade, o gesto espontâneo e a experiência cultural têm sua origem naquilo que o autor denominou de "área de ilusão: a 'mãe suficientemente boa' oferece o seio para que o seu bebê descubra-o e tenha a ilusão onipotente de ter criado o seio - que já estava ali. A criação original é um paradoxo, quer dizer, a criança “cria” ou "descobre” um objeto que já existe e que está posto em sua frente. A fantasia vem antes da objetividade. Um detalhe muito importante, nessa concepção, é que a “mãe suficientemente boa”, também denominada como "ambiente facilitador", deve sustentar amorosamente essa ilusão e, de maneira gradativa, ao permitir que haja falhas no cuidado, possibilitar a adaptação da criança à realidade. A atividade mental do bebê vai ocupar o vazio entre a ilusão (alucinação) e a realidade, isto é, a criança vai aos poucos elaborando as falhas da mãe, quando ocorridas em pequenas doses, compreendendo-as (WINNICOTT, 1975). Insistindo no paradoxo, podemos dizer que o "ambiente facilitador" ilude e, ao mesmo tempo, gradualmente, desilude o indivíduo".

Vale acrescentar que o “ambiente facilitador”, ao dar suporte à onipotência infantil, fortalece o ego frágil da criança, dá sentido aos seus gestos espontâneos, e favorece a constituição de uma personalidade real, o que Winnicott chama de "self verdadeiro". Ao contrário disso, o "ambiente não-facilitador", não é capaz de sustentar a ilusão da criança, é aquele que impõe o seu próprio gesto, cabendo ao infante submeter-se a tal imposição. Isso vai se tornar a base de uma personalidade não-real, um "self falso", um viver não satisfatório, não criativo, com gestos não espontâneos, emprestados de outrem. Mas isso não quer dizer que a criatividade possa ser completamente destruída. Mesmo tornando-se submissa à realidade e estabelecendo uma falsa personalidade, é possível a existência de uma vida oculta satisfatória para a pessoa, permanecendo, não obstante, a insatisfação em virtude dessa vida secreta, não vivida de maneira explícita (WINNICOTT, 1975, p. 99).

Há um contraste entre o indivíduo que sente a vida digna de ser vivida - o sujeito criativo - e aquele que se submete à realidade, trazendo consigo um sentimento de inutilidade. 0 sentimento de que a vida não vale a pena expressa um estado patológico.

Para Winnicott, a criatividade relaciona-se com a abordagem do indivíduo em relação à realidade externa, isto é, o fato de ser uma pessoa ativa e tomar parte da vida em comunidade, já revela que esse indivíduo é criativo. Winnicott vai falar também do seu contrário e daqueles que não desenvolveram essa capacidade de lidar com a vida, com questões cotidianas, de modo criativo, de modo a responder coerentemente às necessidades da vida. A esquizoidia, a esquizofrenia, ou outras espécies de patologias identificadas, exercem influência contrária a uma vida saudável, criativa. Ainda assim - com a criatividade embotada, com o 
sentimento de inutilidade da vida - isso não quer dizer que a capacidade criativa tenha desaparecido de todo, pois, mesmo em casos extremos de submissão ou estabelecimento de uma falsa personalidade, em algum nível, existe uma vida secreta satisfatória. Em síntese, há um vínculo entre o viver criativo e o viver propriamente dito. 0 impulso criativo pode ser reconhecido como algo em si, naturalmente necessário a um artista quando cria, mas também presente quando qualquer pessoa faz deliberadamente alguma coisa e de maneira saudável na lide com a vida.

Considerando o pensamento de Winnicott, infere-se que a escola necessita dar mais espaço à formação de sujeitos autônomos. A criatividade que se estuda aqui se relaciona com a abordagem do indivíduo à realidade externa, supondo-se uma capacidade cerebral razoável, inteligência suficiente para capacitar o indivíduo a tornar-se uma pessoa ativa e a tomar parte na vida da comunidade, pois tudo que acontece é criativo, exceto quando o indivíduo for prejudicado por fatores ambientais que sufocaram esses processos. Portanto, para nós, a instituição educacional, no caso, os insti-

\subsection{A VISÃO DE BROUGÈRE SOBRE JOGO}

Brougère (1998), numa interpretação sócio-antropológica do jogo, discorda da corrente psicanalítica, segundo ele, de inspiração romântica. 0 autor vê, no brincar, o espaço de criação cultural por excelência. No seu entender, essa concepção do brincar torna-o uma instância do indivíduo isolado das influências do mundo. Portanto, o jogo, para ele, não é uma dinâmica interna do indivíduo. Em lugar de desenvolvimento da cultura, ele enxerga, no jogo, o lugar de emergência e enriquecimento de uma cultura lúdica: é uma acumulação de experiências desde bebê; é interação social e alimenta-se da cultura geral.

Gilles Brougère é professor de Ciências da Educação na Universidade Paris XIII e, desde os anos 1970 do século $X X$, se dedica aos estudos sobre o universo tutos de formação de professores, deve, antes de tudo, respeitar o imaginar, o brincar de todo ser humano. Quando livres para criar, os indivíduos, segundo Winnicott, vêem, no estudo, um modo de exercitar o poder de invenção. Se, no entanto, o ambiente escolar não for aberto à brincadeira e à vivência da ludicidade, as aulas serão mais opressoras ou supostamente sérias, embotando o potencial criativo dos estudantes.

Winnicott, em síntese, situa o brincar como ação externa, dialeticamente relacionada ao mundo interno do indivíduo. Para a visão que defendemos aqui, o autor produz uma importante síntese entre mundo objetivo e mundo subjetivo, mundo externo e mundo interno. Concordamos com a ideia de que o próprio mundo externo é uma produção da subjetividade do sujeito, e que a subjetividade do sujeito é, também, uma produção das provisões ambientais. Sendo assim, o fenômeno lúdico, embora trate de um sentimento interno de satisfação, se relaciona, dialeticamente, com o brincar - que é uma ação externa, eminentemente cultural, como podemos depreender da visão de Gilles Brougère, importante estudioso sobre o assunto.

infantil e a ludicidade. No seu livro Jogo e Educação (1998), trata das relações entre jogo e educação do ponto de vista antropológico, filosófico, psicológico, sociológico e pedagógico. Procede a uma profunda análise sociológica para chegar às suas conclusões acerca do lugar do jogo no universo infantil e na natureza humana.

O autor aborda o jogo, principalmente do ponto de vista filosófico, cogita sobre a etimologia da palavra e conclui pela polissemia do termo. Segundo Brougère, a cultura lúdica torna possível a aprendizagem do lúdico. Isto é, a pessoa que participa da cultura, aprende a jogar. Distingue o jogo em três acepções centrais:

a) 0 jogo como atividade lúdica, tanto do ponto de 
vista do sentimento de quem participa desse tipo de atividade, como pelo seu reconhecimento objetivo;

b) 0 jogo como uma estrutura ou sistema de regras (existe e subsiste de modo abstrato independente dos jogadores);

c) E o jogo como material ou objeto (tal como jogo de xadrez e outros), podendo ser associado, também, ao termo "brinquedo".

Considerando, como Wittgenstein, que as palavras são atos, Brougère afirma o caráter polissêmico do termo "jogo", proveniente, pois, de diversas culturas com seus modos próprios de linguajear e criar formas de jogar ou brincar (sem distinguir esses dois termos). Nesse sentido, a noção de jogo, para o autor, emerge da compreensão do seu lugar em diferentes contextos sociais, sendo por ele considerado como um fato social.

Segundo Brougère (1998), nenhuma ciência chegou a construir um conceito operacional de jogo, a não ser a teoria dos jogos, construída em 1944 por Von Neumanne Morgentern (matemático e economista, respectivamente) e que estuda as formas gerais do conflito e cooperação que emanam dessa atividade a partir de modelos matemáticos. A Psicologia vai se utilizar da ideia de jogo como uma noção proveniente do senso comum, trabalhada pela sociedade, pela língua e sem críticas. Para o autor, mesmo Piaget, que tenta elaborar uma explicação psicológica e biológica do jogo, não chega a estabelecer um conceito de jogo. A psicologia, assim, vai fazer um uso comum do termo em diferentes estudos, aplicando-o em certo número de comportamentos e situações. Para os psicólogos, a maioria deles, o jogo também não é um fim, mas, um meio de estudo e interpretação de casos e situações psíquicas para a compreensão do comportamento humano. Para muitos pedagogos, também, o jogo é um meio para se chegar a aprendizagens específicas e contribuir para o desenvolvimento humano.

Na perspectiva da contribuição dos filósofos, Brougère vai ao pensamento de Aristóteles para sustentar que, desde a Antiguidade, a ideia de jogo e jogar se opõe às atividades ditas "sérias". 0 jogo não tem um fim em si e está submetido ao trabalho que o justifica - significa, pois, o espaço para o relaxamento necessário. Coube a Tomás de Aquino introduzir, no universo cristão, a ideia de jogo como injunção divina que orienta o homem ao trabalho e à especulação contemplativa: "Procuramos o repouso do espírito através dos jogos, seja em palavras, seja em ações. Portanto é permitido ao homem sábio e virtuoso propiciar-se esses relaxamentos algumas vezes". 0 jogo tem a finalidade do repouso, justifica Aquino: "se o jogo carregasse em si sua finalidade, deveríamos jogar sem parar o que não poderia ser. Em consequência, as atividades práticas encontram sua finalidade nas atividades especulativas, assim como todo agir humano, na contemplação intelectual” (AQUINO apud BROUGÈRE, 1998, p. 28).

No final do século XIX a humanidade assiste ao nascimento da psicologia da criança e, na sua esteira, os discursos sobre o jogo e a educação. Para Brougère, o novo discurso científico incorpora princípios e quadros teóricos de outras ciências. Os primeiros textos no Romantismo são escritos por poetas ou educadores, mas nesse período do século XIX e início do século XX novos quadros científicos se desenvolvem e buscam explicar os fenômenos do desenvolvimento humano, especificamente, no universo infantil, incluindo, no seu bojo, princípios como o da teoria da recapitulação, advindos da biologia: "Na biologia, alguns quadros de pensamento terão muita influência: a teoria da recapitulação a partir da embriologia comparada ou evolutiva, a teoria dos instintos a partir do que se tornará etologia ou o estudo do comportamento dos animais" (BROUGËRE, 1998, p. 79). Segundo Brougère (1998), a teoria da recapitulação pode ser resumida na metáfora das idades ou da vida, ou seja, na tentativa de comparar a vida da humanidade à vida do indivíduo. Assim como o indivíduo, a humanidade teria também uma infância, uma maturidade e uma velhice.

Constatar-se-á, na esfera da psicologia infantil, em Piaget, o notório cientista a fundar sua psicologia 
evolutiva com forte influência da Biologia. Para ele, o caminho é orientar-se pela criança, pela gênese, para compreender a inteligência adulta. A gênese nesse caso pode ser a do indivíduo como a das próprias ciências, ou seja, da história da inteligência das espécies. Muito embora Piaget não reproduza a teoria da recapitulação nos fundamentos da sua própria teoria (o autor percebe que as leis do desenvolvimento mental não podem repetir a história dos nossos antepassados porque também nossos antepassados passaram por processos de desenvolvimento mental sem ter a quem recapitular), o seu pensamento surgiu num contexto em que a biologia era a ciência mais valorizada e, ele mesmo, como biólogo, buscava explicar o fenômeno da inteligência mediado por modelos biológicos, considerando a psicogênese como parte da embriogênese. Na teoria piagetiana o jogo não é visto em si, mas, como uma atividade espontânea da criança que permite a interpretação de suas representações em diferentes fases, levando à compreensão de suas funções semióticas.

Em Freud, o jogo é um mecanismo de interpretação da subjetividade infantil.

\begin{abstract}
Trata-se de um fenômeno comportamental que nunca foi estudado por si mesmo, mas em relação a outros fenômenos, tais como o chiste ou a criação literária, ou em função do que ele revela como a pulsão de morte através da repetição. [...] Não há pensamento sobre jogo em Freud, nem o haverá, até que o jogo se torna, com Melanie Klein, meio de cura analítica de crianças (BROUGERE, 1998, p. 90).
\end{abstract}

A psicologia, em suma, assim constituída de bases românticas e na biologia, constrói uma ciência sobre o jogo, como um fenômeno natural, ocultando sua dimensão social e concedendo-lhe o lugar da expressão espontânea, própria, natural da criança. É nesse bojo que Froebel citado por Brougere (1998) e Claparède citado por Brougere (1998), por exemplo, associam tais princípios à pedagogia. Vemos, então, surgir um campo de conhecimento educativo - a pedagogia que vai se utilizar de princípios provindos da moderna psicologia infantil e, numa perspectiva que também associa o romantismo às bases da biologia, faz emergir um novo conceito de jogo e de educação infantil.

No final do século XIX, o jogo adquire um estatuto educativo que convém abordar. São três as acepções que assume: como recreação, como artifício para fazer emergir o desejo de aprender e como exercício físico. Duas ideias estão presentes na recreação: a) Jogos organizados pelos professores; b) Como momento de liberdade concedida à criança - um momento educativo enquanto tal e sem qualquer intervenção adulta.

No conceito de jogo, a eterna oposição entre o sério e o não-sério se faz presente até os dias atuais. O jogo oscila entre o sério e o não-sério, conforme o ponto de vista adotado. Mesmo na esfera educativa, quando o jogo está associado ao sucesso escolar de crianças, ou mesmo de jovens, esse sucesso se dá pela compreensão de que o jogo está a serviço da educação, é um meio. Na oposição ao trabalho, ele surge como o relaxamento ou recreação necessária, como trabalho ou atividade séria, serve como meio, a serviço de uma "boa causa” - assim, não é o jogo em si mesmo que contribui para a educação.

A ruptura romântica, com a valorização da infância, concedeu tom de seriedade ao jogo, mas, até nossos dias, essa visão vem se confrontando com o jogo como futilidade, ou atividade não-séria, no sentido do relaxamento ou da recreação. Com inspiração em Piaget, o jogo foi adotado como estratagema em várias pedagogias provindas da escola nova. 0 jogo tem sido adotado em pedagogias libertárias como atividade livre - e essa é uma herança do naturalismo que se originou no Romantismo. De uma forma ou de outra, é assim que o jogo tem sido veiculado ou assumido nas escolas de educação infantil na atualidade.

Finalmente, pode-se dizer que o jogo tem um conceito paradoxal e polissêmico; todavia, mesmo assumido como atividade espontânea, possui enraizamento social, disso não se pode desviar. Seja como for e pelas razões expostas, para Brougère, somos ainda românticos. 


\subsection{LUCKESI E O CONCEITO DE LUDICIDADE VINCULADO À SUBJE- TIVIDADE HUMANA}

Como mencionamos no início deste capítulo, para Luckesi (2006), a ideia de ludicidade está associada à experiência interna dos indivíduos. 0 conceito de ludicidade para esse autor se expande, pois, para além da ideia de lazer restrito à experiência externa, ampliando a compreensão para um estado de consciência pleno e experiência interna:

[...] quando estamos definindo ludicidade como um estado de consciência, onde se dá uma experiência em estado de plenitude, não estamos falando, em si das atividades objetivas que podem ser descritas sociológica e culturalmente como atividade lúdica, como jogos ou coisa semelhante. Estamos, sim, falando do estado interno do sujeito que vivencia a experiência lúdica. Mesmo quando o sujeito está vivenciando essa experiência com outros, a ludicidade é interna; a partilha e a convivência poderão oferecer-lhe, e certamente oferece, sensações do prazer da convivência, mas, ainda assim, essa sensação é interna de cada um, ainda que o grupo possa harmonizar-se nessa sensação comum; porém um grupo, como grupo, não sente, mas soma e engloba um sentimento que se torna comum; porém, em última instância, quem sente é o sujeito (LUCKESI, 2006, p. 6).

Nesse sentido, o conceito do que é lúdico repousa sobre a ideia do prazer que reside no que se faz, como algo que reside em nós e no modo como nos relacionamos com o mundo. 0 conceito de Luckesi (2006) parte do ponto de vista da subjetividade do sujeito. 0 autor associa a ludicidade a estados de consciência implicados na prática de atividades lúdicas, sintetizando-os em dois: estado de consciência focado e estado de consciência ampliado. Os seres humanos estariam, segundo o autor, usufruindo desses atos/estados ao longo da vida, mas a fixação em um ou outro representaria algum tipo de distúrbio.

Distinguindo clareza de exatidão, o autor conclui, inspirado no físico Heisenberg, que a clareza se refere a uma compreensão a partir de múltiplas possibilidades, e a exatidão se refere a precisão, a limites bem definidos. Nesse caso, do conceito de consciência focada e ampliada, o autor vai se reportar à ampliação da consciência com o ser inclusivo, portanto, com o conceito de clareza. Ao contrário, a orientação na vida cotidiana baseada apenas na exatidão das coisas e dos conceitos levaria a um modo de viver fragmentário e restritivo. 0 ato mental vai exigir, portanto, vivenciar a riqueza das múltiplas possibilidades, numa perspectiva inclusiva, o que não é o caso do olhar as coisas pelo sentido da exatidão. Não obstante, a exatidão nos seja necessária também no dia-a-dia em ações precisas em que o ser humano necessite de concentração e de decisões que não admitam momentos de imprecisão, como no caso de conduzir um veículo e seguir as leis de trânsito, por exemplo. Se não seguirmos rigidamente, precisamente, as leis de trânsito, corremos riscos e colocamos a vida de outrem em risco também.

Na prática da pesquisa científica, assim como na composição de uma música, ou escrita de um livro, vamos precisar muito mais do sentido criativo que inclui a clareza, ou uma visão carregada de múltiplas possibilidades, do que da exatidão ou visão precisa das coisas. Conclui Luckesi (2004, p. 17): “Em síntese, clareza significa ampliação da consciência que se caracteriza pela inclusão, e exatidão significa focalização da consciência. Nós necessitamos dos dois polos da dialética permanente entre um e outro estado para podermos criar, recriar e viver o cotidiano".

Com esse conceito, o autor afirma que as atividades lúdicas vão desencadear a dialética desses estados de consciência: focado e ampliado. A consciência amplia-se para que o participante possa escolher a forma mais adequada de realizar a tarefa e foca-se para que possa efetivamente realizar essa mesma tarefa.

Na vivência das brincadeiras, usualmente, o tempo de permanência em cada um dos estados de consciência, 
dialeticamente relacionados é pequeno. Por vezes, usa-se um átimo de tempo em ou outro dos estados de consciência, pois que as decisões e os atos necessitam ser muito rápidos, a fim de participar de tudo que ocorre (LUCKESI, 2004, p. 19).

Luckesi (2004) sustenta que as atividades lúdicas, por propiciarem experiências plenas, poderão também propiciar o acesso a sentimentos os mais profundos, inconscientes, tornando-se um referencial de expansão para o individuo. A vivência da ludicidade poderá permitir, assim, integrar níveis de consciência dos mais sutis, constituindo expediente ou forma de prevenir neuroses futuras, seja no contexto da sala de aula, seja no contexto terapêutico. As práticas lúdicas no contexto pedagógico funcionariam como recursos de formação e também de autodesenvolvimento.

Segundo Pereira citado por Porto (2004, p. 68), uma prática voltada para a educação lúdica exige a imprevisibilidade e que o professor abra mão do controle absoluto, dando espaço para a auto-expressão e criatividade dos alunos, possibilitando o autoconheci- mento e o autodesenvolvimento destes.

As atividades lúdicas permitem que vivenciemos com inteireza um espaço-tempo próprio, que estejamos plenos na experiência, nos entregando a ela sem julgamentos, sem coerções, sem imposições e direcionamentos controladores, com abertura para novas possibilidades. Assim, considero como lúdicas não apenas as atividades que envolvem brincadeiras e jogos, mas também aquelas que possibilitam que se instaure esse estado de inteireza e entrega (PEREIRA apud PORTO, 2004, p. 82-83).

A autora se refere a outras atividades, como, sensibilização, dinâmicas de integração, recorte e colagem, canto, dança, etc. Atividades usadas na sala de aula que estão para além do que se convencionou chamar de atividades lúdicas.

A vivência da ludicidade, pois, permitirá a flexibilização do comando racional das coisas, expandindo a consciência e nos livrando das defesas do ego. A absorção no fazer, a integração e entrega total e plena, interconectando o fazer, o sentir e o pensar, caracterizarão o estado de ludicidade conceituado por Luckesi (2002; 2004).

\section{3 À GUISA DE CONCLUSÃO}

Com este estudo, tivemos por objetivo instigar o debate acerca de novas possibilidades de se pensar a educação à luz de uma perspectiva epistemológica mais ampla e que contemple a construção do conhecimento a partir de múltiplas referências, de modo que o elemento lúdico possa vir a ocupar plano apropriado na educação. Por essa via, uma prática educativa efetivamente lúdica permitirá exercer a profissão docente mais criativamente.

O conceito de ludicidade que defendemos, pois, se articula a três dimensões: a) a de que o brincar e, de forma mais ampliada, as atividades lúdicas são criações culturais, são atos sociais, oriundos das relações dos homens entre si na sociedade; b) a ludicidade é um estado de ânimo, um estado de espírito que expressa um sentimento de entrega, de inteireza, de vivência plena, e diz respeito à realidade interna do indivíduo; c) nesse sentido e pensando a ludicidade como princípio formativo, defendemos a ideia de que as atividades lúdicas se façam presentes na sala de aula como elementos estruturantes do processo de ensinar e desencadeadores de aprendizagens significativas - aquelas em que o ser humano precisa integrar suas capacidades de pensar, agir e sentir, sem hipertrofiar o que a escola, com toda sua tradição iluminista, hipertrofiou por séculos - a dimensão intelectual, em detrimento do sentimento, do saber sensível, da intuição e da ação sobre o mundo. 


\section{REFERÊNCIAS}

BETTELHEIM, Bruno. Uma vida para seu filho: pais bons o bastante. Rio de Janeiro, RJ: Campus, 1989.

BROUGÈRE, Gilles. Jogo e educação. Porto Alegre: Artes Médicas, 1998.

BROUGĖRE, Gilles. A criança e a cultura lúdica. In: KISHIMOTO, Tizuko (org.). 0 brincar e suas teorias. São Paulo, SP: Pioneira Thomson, 2002. p. 19-32.

GOMES, Daniela. A ludicidade na educação: por uma formação lúdica do professor de língua inglesa. In: PORTO, B. S. (org.). Educação e ludicidade: ensaios 3. Salvador, BA: UFBA. p. 141-158, 2004.

HUIZINGA, J. Homo ludens. São Paulo, SP: Editora Perspectiva, 2004.
LUCKESI, Cipriano. Estados de consciência e atividades lúdicas. In: PORTO, Bernadete. Educação e ludicidade. Ensaios 3. Salvador: UFBA, 2004, pp. 11-20.

LUCKESI, Cipriano. Ludicidade e atividades lúdicas: uma abordagem a partir da experiência interna. Disponível em: www.luckesi.com.br. Acesso: mar. 2006.

PEREIRA, Lúcia Helena Pena. Ludicidade em sala de aula: montando um quebra-cabeça com novos sabores e saberes. In PORTO, Bernadete (org.). Educação e ludicidade. Ensaios 3. Salvador: UFBA, 2004.

SANTOS, Maria José E. Ludicidade e educação emocional na escola: limites e possibilidades. Dissertação de mestrado. Salvador, BA: FACED/UFBA, 2005.

WINNICOTT, D. W. O brincar e a realidade. Rio de Janeiro: Imago, 1975. 